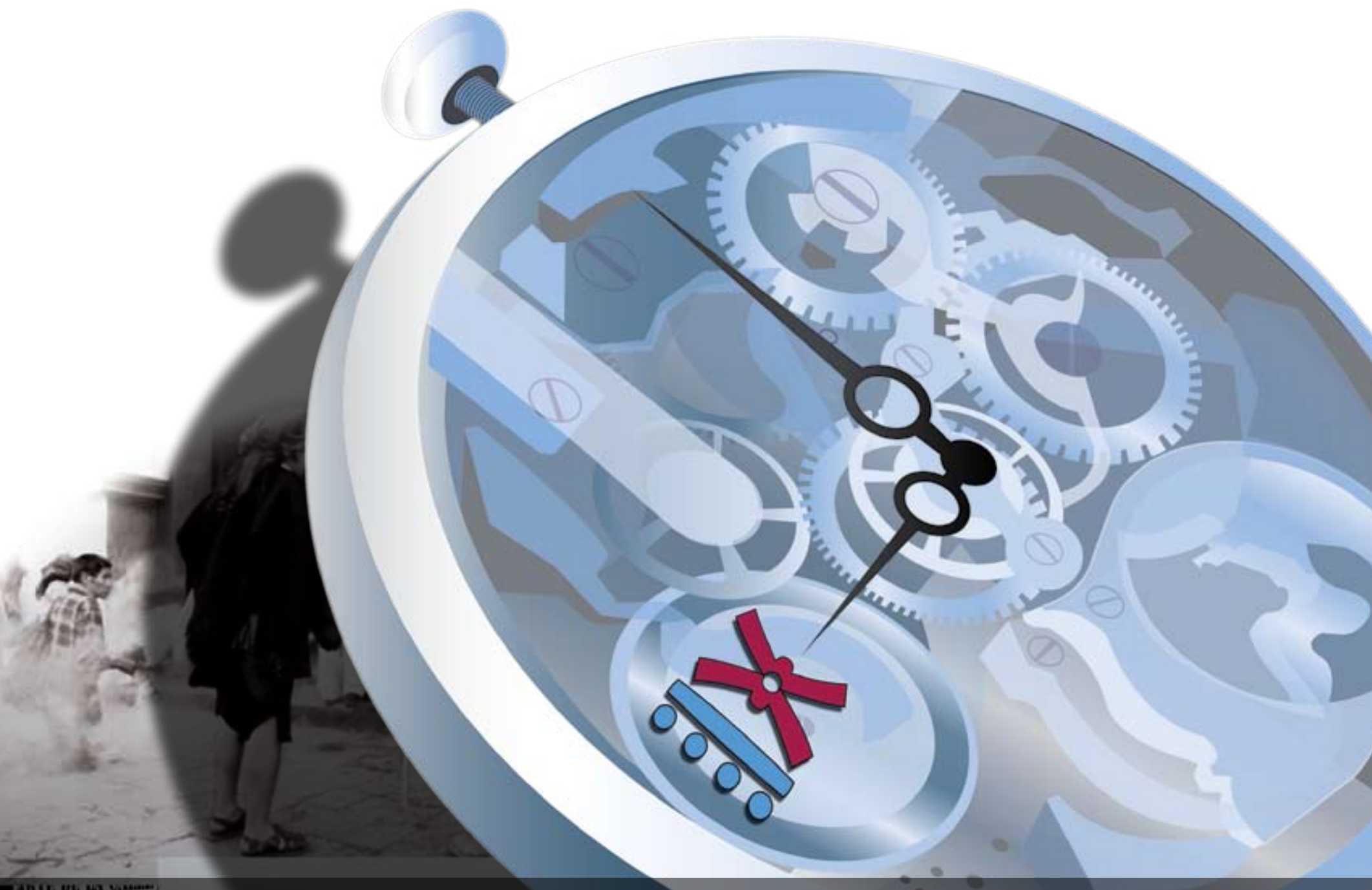

$9^{\circ}$ C O N G R E S O CENTROAMERICANO DE H ISTO R I A

Universidad de Costa Rica ISSN 1409-469X

Fecha de recepción: 15 de mayo 2008 Fecha de aceptación: 30 de mayo 2008

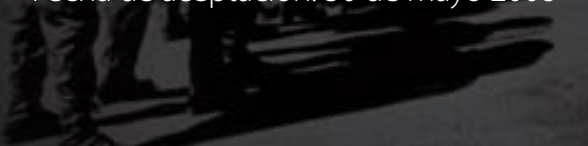

Revisión de políticas urbanas impulsadas en la ciudad de Caracas durante las cuatro primeras décadas del siglo XX
Miembros del Consejo Editorial:

Dr. Ronny Viales, Dr. Juan José Marín

Editores Técnicos:

Allan Fonseca, Andrés Cruz, Gabriela Soto
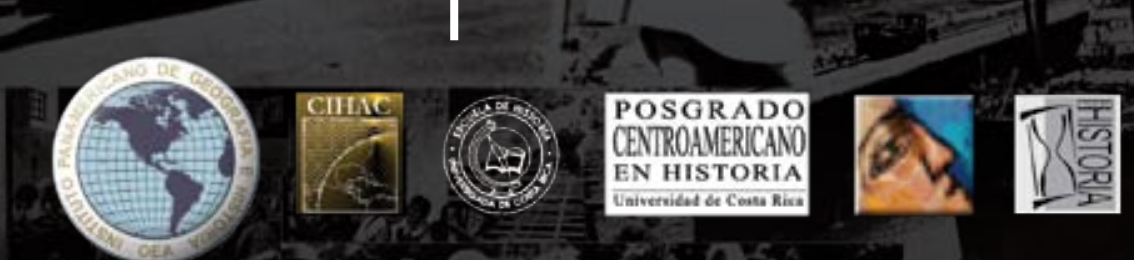


\title{
Revisión de políticas urbanas impulsadas en la ciudad de Caracas durante las cuatro primeras décadas del siglo $\mathrm{XX}$
}

\author{
Reynaldo Díaz
}

Universidad Central de Venezuela- Ciudad UniversitariaCaracas/Venezuela 00584129779877 reyrey871@gmail.com / reyrey871@yahoo.es

Actualmente se desempeña como Investigador en el COPRED, Institución destinada a la preservación, conservación y resguardo de la documentación y obra construida que conforma la Ciudad Universitaria de Caracas, declarada Patrimonio de la Humanidad por la UNESCO en 2000. Ha trabajado con las instituciones garantes del patrimonio arquitectónico y cultural del país. Articulista de la revista de arquitectura de mayor trayectoria en el país. Revista: Entre Rayas. reyrey871@ gmail.com. 


\section{Introducción}

Una vez consumada la ruptura del nexo colonial existente entre los países latinoamericanos (específicamente Venezuela) y la corona española, los sectores dirigentes se dedicaron a la labor de organizar espacialmente sus territorios. Venezuela una vez superada la cruenta guerra de emancipación, no se consideraba así misma como unidad territorial, producto del intenso proceso de mestizaje ocurrido en el territorio; y también, debido a que, en el país se encontraban muchos descendientes directos de colonizadores.

Muchos fueron y continúan siendo los caminos y estrategias trazadas para unificar la sociedad venezolana como vías de comunicación, mejoras en el terreno urbano, políticas gubernamentales. Es precisamente durante las cuatro primeras décadas que el estado nacional impulsa serias y decidas acciones para el ordenamiento urbano y espacial; el cual se venía realizando por acciones espontáneas y de privados que no consideraban una totalidad; sino que se basaban y atendían parcialidades.

Estas propuestas debían atender el rápido incremento demográfico evidenciado en la población nacional, procesos migratorios de campo a la ciudad, el déficit habitacional, la llegada del automóvil a la dinámica urbana y hondos problemas sanitarios.

Son muchas las medidas tomadas y por distintos personajes del acontecer político, teniendo como resultado la presentación del único plan de desarrollo urbano para la ciudad capital denominado el Plan Rotival a causa de su propulsor. En las siguientes líneas se desarrollara las ideas antes expuestas y los aspectos que condicionaron su aplicación. 


\section{BREVE RESEÑA DE LA EVOLUCIÓN DE CARACAS}

La ciudad colonial, ha legado su trama urbana como marco referencial y protagonista en la dinámica de la ciudad. El diseño primigenio de la ciudad- herencia y lección española -se planeó según la forma de tablero de ajedrez, caracterizado por calles rectas y perpendiculares y la Plaza Mayor ubicada en el centro de la composición; orden establecido por las Leyes de Indias ${ }^{1}$ y común a todo el urbanismo hispano-americano. Luego de su fundación, se da la apertura a un pausado y arduo proceso de inserción hacia las diversas formas de modernidad que se harán presentes hasta nuestros días.

..."el trazado cuadricular marcado por Diego de Henares en el momento de la fundación de la ciudad, adquiere valor de elemento originario y persiste en el contexto de la metrópoli actual. La apertura de nuevas avenidas, el ensanche de las viejas calles y modificaciones impuestas por las exigencias de la vida contemporánea, tienen que adaptarse y solucionarse sobre la base del trazado que sirvió de asiento a la pequeña aldea del siglo XVI. Es este un claro ejemplo de persistencia del plano y, al mismo tiempo, el documento más antiguo con que cuenta la ciudad."

La Caracas de Maricastaña ${ }^{3}$ fue principalmente una ciudad uniforme y de sobria 1 Es adecuado reconocer la importancia de las instrucciones contenidas en esas Leyes; en efecto, estas comprenden las reglas y disposiciones para la fundación, construcción y ordenamiento de las ciudades hispanas; tomando en consideración aspectos como: clima, las aguas, vientos; entre otros

2 Graziano Gasparini y Juan Pedro Posani. Caracas a través de su arquitectura, (Caracas, Venezuela: editado por la Fundación Fina Gómez, 1969), 198.

3 En diccionarios etimológicos se reconoce la acepción Maricastaña como personaje propio de antigüedad remota, sin período cronológico específico, comúnmente es empleado en ex- 
composición volumétrica. La disposición de las casas-herencia de griegos y romanos- fue implantada por los alarifes del sur de España; el patio principal construido entre arcos rebajados sobre pilares toscanos o panzudos, constituía el epicentro de distribución entrono al cual se disponían las piezas principales destinadas al recibo, comedor y alcobas; generalmente en la parte posterior se cultivaban jardines y huertas de toda clase, el heredado zaguán constituía el elemento de transición entre el espacio público y privado.

Durante el prolongado período de entreguerras, en materia urbana y arquitectónica no se producen destacados adelantos; culminada la etapa son contadas las edificaciones- construidas o en pie- que recibe el nuevo orden gubernamental.

Desde mediados del siglo XIX se dejó prolongar la frágil trama del damero colonial, sin prever la composición del valle, así como tampoco los cambios introducidos en los sistemas de transporte, las plazas progresivamente van perdiendo su condición de fórum, la manzana se disuelve, se construyen nuevas casas en las áreas destinada a jardines y huertas, estas se dividen en unidades más pequeñas, en lotes estrechos y largos; los patios se reducen y pierden los espacios verdes que tenían en su centro.

"Pasan los años y Caracas sigue extendiéndose con gran rapidez, como una mancha de aceite, por todos los rincones del valle, sin orden y sin principios definidos. No es ya propiamente una ciudad, sino que la forman diferentes moléculas; es la dislocación del centro urbano: la ciudad colonial explotó literalmente en espacio de poco tiempo." ${ }^{4}$

Finalizadas las guerras de independencia en la segunda década del siglo XIX, la estructura de nuestras economías quedan esencialmente inquebrantables, la ruptura del vinculo presiones como: En los tiempos de Maricastaña.

4 Carlos Raúl Villanueva. La Caracas de Ayer y de Hoy su Arquitectura Colonial y La Reurbanización de EL Silencio, (Caracas, Venezuela: Editado por la Comisión del Cuatricentenario de la ciudad, 1950), 6 . 
con la Corona española, marcó el inicio de una etapa de paralización mientras se crean las condiciones básicas para establecer los nexos comerciales con los países emergentes. "En la fase pos-independentista encontramos entonces el crecimiento de las economías latinoamericanas va depender de su potencial para ofrecer (...) las nuevas materias primas que se demandan."

Es a partir de la segunda mitad del siglo XIX cuando se producen en Caracas nuevos y decididos intentos de reorganización, reflejo de los indicios de cierta estabilidad política. La pregonada idea de "progreso" experimenta su primera materialización de la mano del General Antonio Guzmán Blanco ${ }^{6}$, durante su mandato Caracas pasó a ser el principal foco de su gestión gubernamental: transformar su imagen aldeana a la de una urbe civilizada, con infraestructura urbana, servicios, edificios públicos y espacios urbanos renovados; inspirados en el modelo urbano francés, fue el puntal de su administración e impulsar la imagen digna de una Capital Federal.

"Este primer impulso de modernización, que apenas logró una mínima parte de sus propósitos, produjo un fuerte impacto en la imagen de Caracas. La modificación de la escala volumétrica de los edificios y los criterios ornamentales establecidos, fueron aceptados por la sociedad civil y e incorporados a su deseo de renovación. (...) La nueva imagen de la "Capital Federal" lograda por la gestión guzmancista entre el "Septenio" y la "Aclamación", tuvo eco en las construcciones privadas y se convirtió en un precedente aleccionador para los sucesivos

5 Marco Negrón. 4 Conferencias introductorias al estudio de la Urbanización, (Caracas, Venezuela: Ediciones de la FAU-Sector Estudios Urbanos, 1980), 62.

$6 \quad$ Las intenciones de reforma urbana de Caracas del Ilustre Americano, se inscriben antes de su primera presidencia, ya como gobernador de la ciudad en 1865, decreta la mudanza del mercado de la Plaza Mayor y su transformación en paseo arbolado en homenaje a Simón Bolívar. Como primer mandatario su nuevo programa de obras públicas estuvo orientado a consolidar el poder de la capital sobre el resto del territorio nacional, la capital se convirtió en la principal ciudad venezolana en cuanto a concentración de poder y de población, con una infraestructura urbana, de servicios y ornato no comparable con ninguna otra población del país. 
gobernantes durante las dos décadas siguientes..."

La innovación más marcada de este período consiste en el inicio de una política estatal para el ornato de los espacios públicos que combinaba una ingenua pretensión de monumentalidad con un empleo de la vegetación conforme con los patrones de la jardinería francesa. Esta política estaba dirigida al realce de los sitios de esparcimiento de la clase dominante y confidencialmente, a la propaganda arquitectónica de un régimen autocrático que se decía liberal y europeizante. Es así como se inicia, a opinión de diversos autores el uso político de los espacios públicos.

En materia urbana se consumó un cambio fundamental en las condiciones sanitarias de la ciudad, con la construcción del acueducto Guzmán Blanco el cual reemplazó el inicial sistema colonial de canales cubiertos que abastecían las fuentes públicas, ubicadas en algunas de las plazas urbanas. Esta labor se complementó con otras como la disolución de cementerios en el área urbanizada de la ciudad y la apertura de un nuevo camposanto a las afueras; de igual manera, la construcción del nuevo matadero y la reorganización de los mercados públicos.

"Si bien no podemos hablar de la existencia de un plan urbano, con sustentación teórica y estructura orgánica, para la transformación de la capital federal, todas las realizaciones apuntaron hacia la consolidación económica, política, social y urbana de Caracas, lo que fue mucho más allá de ese "fachadismo" con el que tradicionalmente se ha calificado la obra de Guzmán Blanco; producto de ello se vieron estimuladas la migración a la capital y el crecimiento poblacional, en las décadas siguientes." 8

La ciudad de Caracas inicia un nuevo milenio seriamente castigada por el terremoto de 1900, dicho sismo evidencio ante los caraqueños que buena parte del cambio introducido a fines

$7 \quad$ Ciro Caraballo Perichi. "Los últimos días de aquella de los techos rojos, o los planes antes del plan" en El Plan Rotival la Caracas que no fue, ed. Marta Vallmitjana, (Caracas, Venezuela: Ediciones Instituto de Urbanismo FAU-UCV, 1991), 49.

$8 \quad$ Ibid., 54. 
de siglo XIX requería también, de una modificación en las técnicas y materiales de construcción; Paralelamente, el desplome de buena parte de viviendas que servían de oficinas públicas, evocó la necesidad de continuar el programa de construcción de edificios públicos iniciado por Guzmán Blanco.

Surge un nuevo personaje en el acontecer nacional, el cual viene proseguir a partir de 1904 los planes de transformación urbana de la era guzmancista. Es así como el nuevo mandatario nacional: Cipriano Castro, con nuevas posibilidades económicas y tecnológicas, dará apertura a un nuevo ciclo de auge constructivo; por esta vía, la realización de edificios públicos aderezados de ornamentos a la francesa, representaran su mayor expresión, siendo de menor significado las obras de infraestructura y servicios.

Como parte de las acciones de organización y mejoras urbanas promovidas durante el período, destaca la disposición de la Gobernación del Distrito Federal que instituyó como obligatoria la figura del ingeniero para la directriz de las construcciones en la ciudad. En lo urbanístico, el mayor aporte se encuentra en la consolidación de un nuevo núcleo residencial capitalino, imagen de la Caracas ideal de principios de siglo: la Urbanización El Paraíso.

Su consolidación fue posible, en buena medida, a las elevadas inversiones en infraestructura urbana realizadas por el Ministerio de Obras Públicas, puentes y avenidas que facilitaban la rápida comunicación con el centro de la ciudad, calles y aceras, obras de ornato y recreación.

Por vez primera se provoca una fractura, en lo que hasta el momento permanecía como el esquema básico de la dinámica de la ciudad, si bien se había consolidado las funciones del casco tradicional, como sede administrativa, financiera y comercial; su uso residencial se vio diezmado con el fortalecimiento de áreas residenciales adyacentes. 
... "la urbanización "El Paraíso", la cual en pocos años pasó a ser el más importante y exclusivo lugar de residencia de las familias caraqueñas de mayores recursos, hasta entonces domiciliadas en el área central..."

\section{Punto de partida de los estudios formales y planificación urbana.}

La población venezolana se desarrollo durante la primera mitad del siglo XX con tres características relevantes: acelerado crecimiento, distribución geográfica desigual y concentración urbana. Estos rasgos son consecuencia de una dinámica poblacional que evolucionó espontáneamente, sin controles ni restricciones formales.

Desde el punto de vista de la tipología del tejido urbano, hasta el primer tercio del siglo XX la ciudad de Caracas se identificaba por estar constituida en su gran mayoría por un tejido uniforme, característico de la colonia y que se repitió sin mayores modificaciones, este tejido se caracterizaba por la utilización de la cuadrícula como base de la estructura urbana.

En la mayoría de los países de Latinoamérica el histórico centro colonial continúa siendo topográficamente el centro de la ciudad moderna; esta es la primera causa de su deterioro ambiental. Inclusive cuando se recuperan algunas edificaciones tradicionales, se ven afectadas con las nuevas realizadas a escala totalmente opuesta.

Lamentablemente el país no cuenta zonas coloniales, conservadas o menos intervenidas que podrían identificarse con la ciudad vieja, como en el caso de Quito, Cartagena o Puebla.

“Caracas es en Venezuela la región metropolitana con preponderancia desproporcionada de grandes aglomeraciones, concentra el crecimiento urbano y constituye el lugar donde se asienta la dirección económica y política del país. (...) La citada "marginalidad" es ante todo

$9 \quad$ Ibid., 58. 
económica, en el sentido de que ella manifiesta al mismo tiempo la segregación residencial del espacio urbano y la incapacidad del sistema de producción de viviendas para tomar en cuenta las necesidades sociales cuando esta demandada no es rentable"10

La rápida expansión urbana experimentada, se presenta como un medio de enfrentar los problemas de higiene, de circulación, de orden público y control del suelo, sobre todo en una ciudad que desconocía la dinámica que se estaba desarrollando y carecía de medios tecnológicos.

Una de las características del urbanismo venezolano en las primeras décadas del siglo XX, consistió en la creación de organismos e instituciones como el Banco Obrero, la Comisión de Urbanismo y la Dirección de Urbanismo; así como la promulgación de un cuerpo leyes, que en conjunto, permitiesen la ejecución de una serie de obras que subsanen los nacientes problemas: demográficos, sanitarios y habitacionales.

... "Francis Violich en su libro Cities of Latin America (1994) (...) entre las mayores diferencias intercontinentales, el planificador resaltó la actitud de muchos gobernantes suramericanos, quienes en general habian hecho un esfuerzo mayor que sus colegas del norte para dejar tras sí obras públicas y asumir un rol en planificar el desarrollo físico de sus ciudades. " 11

Los planes de ordenamiento vienen a ocupar la función de un mecanismo fuerte y potente que suministraría las herramientas necesarias para construir la imagen de la ciudad aspirada. En la Caracas ideal, los planes de organización territorial y vial pasaron de ser un elemento 10 Magaly Sánchez. "Estructura social y política de vivienda en el área metropolitana de Caracas", en Estructura de Clases y Política Urbana en América Latina, ed. Manuel Castells (Buenos Aires, Argentina: Ediciones Nueva Visión, 1974), 145.

11 Arturo Almandoz. Urbanismo Europeo en Caracas (1870-1940),(Caracas, Venezuela: Ediciones de la Universidad Simón Bolívar, 1992), 11. 
funcional relacionador de las actividades del tejido a convertirse en el estructurador de la ciudad y separador de las unidades que la conformarían.

"Si los principios de la economía política, la higiene, la administración pública, la moral y el orden público, así como los puramente técnicos, no están presentes, no hay criterio o sentido de verdad que permita evaluar ningún proyecto (...) los grandes trabajos urbanos que serán emprendidos (...) deberán satisfacer en todos los casos las necesidades que ella engendra, a fin de alojar convenientemente a una humanidad enfilada a un crecimiento y desarrollos continuos. " 12

El programa en obras públicas impulsado por Cipriano Castro perderá continuidad durante el nuevo régimen que dirigía el país a manos del Gral. Juan Vicente Gómez, lo realizado en la capital en el ramo edilicio no compite en suntuosidad y estampa urbana con las edificaciones castristas y guzmancistas. "Las obras urbanas no son en apariencia un renglón de primer orden en el régimen gomecista. Esto contrasta fuertemente con los gobiernos anteriores, especialmente el periodo de Guzmán Blanco, cuando se le dio un gran peso a las obras públicas.

Sin embargo en los primeros años del régimen gomecista, sigue siendo la capital de la República la privilegiada en este respecto, además el gobierno instrumentó en Caracas un vasto programa para dotar a la ciudad de una amplia red de infraestructura vial y de servicios, como nunca antes se había hecho: calles y aceras; modernas avenidas, más de 20 puentes urbanos, el Acueducto y la Red General de Cloacas; Se crearon de esta manera las condiciones idóneas para el acelerado crecimiento que experimentaría la capital.

Sin embargo, mucho se ha escrito sobre cómo a partir del ascenso al poder del benemérito, trajo consigo el cambio del sector oficial con respecto a Caracas; el nuevo gobernante rompiendo 12 Juan José Martín Frechilla. Desde la Arquitectura a la ciudad Moderna, (Caracas, Venezuela: Editado por el C.I.D. F.A.U., 1989), 13. 
con lo que hasta entonces había sido regla, gradualmente fue restándole importancia a la capital en su arraigada función de receptora de inversiones en obras públicas. Se observa claramente el favoritismo por las obras de infraestructura- tanto urbanas como territoriales- antes que por la inversión de edificaciones monumentales, lo cual actuará en beneficio de la economía, las condiciones de vida y el control militar del país.

En el gobierno del General Juan Vicente Gómez, una de las características más relevantes de la política urbana fue la presentación de un nivel supraurbano, en la cual la realización de obras de infraestructura desplazó ampliamente a la ejecución de edificaciones aisladas y de suntuosidad. En el decreto del 24 de julio de 1910 se ordenó la construcción en cada Estado de la República de una carretera central, las cuales constituirían las vías principales de cada entidad federal. Por otra parte, en los centros poblados no sólo se dio prioridad a las obras de infraestructura viales, también se ejecutaron obras de saneamiento, como acueductos, cloacas y drenajes, etc.

Durante el gomecismo se despierta la preocupación de atender el sector salubre del país, cobrando un peso determinante en el desarrollo del proyecto nacional de modernización; motivado a ello y como parte de las actividades conmemorativas del 19 de abril y 5 de julio, se promulgó "un plan general de saneamiento de la ciudad de Caracas, según los principios y reglas de la sanidad moderna.

... "Con mayor o menor rapidez y éxito, los acuerdos del Congreso de Medicina, al igual que el de Municipalidades, se fueron convirtiendo en acciones, por lo menos en papel, en las normas, reglamentos, organismos. Con los médicos por un lado y los ingenieros por otro se reprodujo en el país, en esta primera década del siglo $X X$, una articulación entre salud y ciudad, que dio paso a la legislación sanitaria y luego a la propiamente urbana, acompañada de las 
primeras encuestas." 13

La mirada atenta en lo sanitario, por parte del país y buena parte del continente fue más independiente de la reforma habitacional de lo que había sido en Europa. Las ordenanzas edificatorias y ambientales en las grandes capitales latinoamericanas fueron un intento por responder a las ideas europeas en salud pública.

Producto de esta intensa actividad gubernamental, en marzo de 1909 se crea la provisional Comisión de Higiene Pública para el estudio y resolución de problemas sanitarios, luego en noviembre de 1911, la Oficina Nacional de Sanidad con injerencia en los hospitales, acueductos, cloacas y ensanche y modificación de calles. Pocos meses después es sancionada la primera Ley de Sanidad y en diciembre de 1912 el Reglamento de Sanidad Nacional ${ }^{14}$; en un intento por regular, todo acto referente al aseo, características constructivas y funcionamiento de cualquier edificación urbana.

Posteriormente en 1924 se aprueba la Ordenanza sobre Terrenos de Propiedad Municipal en la que se establecen los términos de arrendamiento, proporción máxima de parcela, su disposición residencial y las normas para su otorgamiento. Sin embargo y a pesar de la promulgación y aplicación de Leyes, Normas y Reglamentos, que perseguían controlar los cambios urbanos de la capital, aquellas, iban a un ritmo menor que el del crecimiento demográfico. Este desfase se evidenciaría claramente con la expansión violenta y caótica de las áreas urbanizadas de la capital entre 1926 y 1936.

13 Juan José Martin Frechilla. "Los Orígenes del Interés Social en las Políticas Públicas de Vivienda en Venezuela 1911 - 1941" Revista Urbana, (Caracas) 16, (marzo-abril 1995): 81. 14 Las alarmas sobre el hacinamiento y la miseria de las casas de vecindad expuestos por Razetti serán considerados en el Reglamento de Sanidad Nacional. Así mismo, la requerida extensión de patios, galerías y viviendas, número de excusados, baños, cocinas y lavaderos; en el capitulo denominado Habitaciones se categorizan las higiénicamente aceptables, insalubres, ruinosas, peligrosas, incómodas e inhabitables. 
En el Reglamento de Sanidad Nacional de 1912 y en la Ordenanza de Policía Urbana y Rural del Distrito Federal de 1910, aparecerán allí por primera vez las bases legales para validar, un proceso de renovación y segregación urbana , estas bases legales estarán acompañadas desde 1909 por una Ley de Expropiación por Causa de Utilidad Pública, ajustada nuevamente en 1912, para permitir que la sola declaratoria de utilidad por parte del ejecutivo o de los municipios permita cualquiera otra obra relativa al saneamiento, ensanche o reforma interior de las poblaciones.

El lema de la modernización que antes se encontraba en manos de la administración guzmancista, fue transferido a manos privadas, quienes con el apoyo de los gobernantes, entre 1920 y 1936 realizaron un desarreglado y aislado proceso de urbanización. Aunque Caracas no impulsó la formación de un plan urbano, análogo a los adelantados en algunas capitales latinoamericanas, sí permitió emitir cierta trasformación espacial, a fin de lograr dar solución a determinados problemas de tránsito vehicular.

"El verdadero elemento que estructura el espacio urbano de Caracas en este siglo se realizó mediante la construcción de su infraestructura de vialidad. No podemos negar la evidente relación entre la construcción de urbanizaciones desarrolladas en el período analizado y la del sistema de vialidad del Valle de Caracas, una no se puede explicar sin la otra (...) su sistema vial es el elemento que la marca con mayor fuerza, la determina, identifica y singulariza."'15

Entre 1926 y 1936, la ciudad prosperó y se transformó a un ritmo y nivel ignorado, conjuntamente se afianzaron las tendencias de segregación social y funcional de las distintas zonas de la ciudad, proceso previamente iniciado en el siglo XIX. Para 1925 el país ingresaba a pasos firmes en la comunidad de los países productores de petroleros, por vez primera el ingreso

15 Frank Marcano Requena. "La ciudad: Laboratorio de Modernidad", en Caracas Memorias para el Futuro, ed. Giuseppe Imbesi (Italia: Gangemi Editore, 1995), 191. 
por concepto de exportaciones de hidrocarburos era superior al obtenido por las tradicionales exportaciones del país agrícola; Caracas se modernizaba al impulso de la nueva riqueza.

Dentro de este apogeo modernizador, el automóvil se proclamaba como el gran protagonista, su presencia, cada vez más contundente, marcó un nuevo sello al caso central de la ciudad, el cual se vio trastocado, sin sospechar el caos por venir. Variados serán sus efectos: por una parte permitió a los caraqueños establecer su residencia en las afueras de la ciudad, como es de esperar propició la transformación urbana, así como la presencia de nuevas tipologías arquitectónicas, congestionamiento del tráfico, contaminación sónica, arrollamiento de peatones, garajes para vehículos, iluminación pública en postes de gran altura, entre otros; por tanto el centro de la ciudad, dejo de ser para definitivamente una zona residencial, para especializarse en funciones administrativas y comerciales.

La urgencia de un trazado vial que solucionase los problemas del creciente tráfico automotor de Caracas en esos años, la localización de las edificaciones que requiere un Estado en expansión, la normativa para el control del crecimiento y expansión de la ciudad, resumen, los inconvenientes que requerían una pronta y efectiva solución. Entre la renovación y extensión se escoge la renovación; entre el posible desplazamiento del centro urbano como resultado de la “amenaza de muerte de la ciudad tradicional” se escoge su valorización.

... "la declarada agresión contra el entorno caraqueño comienza, fundamentalmente, con la explotación y comercio del petróleo en Venezuela, elemento éste que modifica, radicalmente, la economía del país. Pasar de la producción agrícola, basada en el cultivo, principalmente, de café y cacao, para ingresar a la extracción y comercialización del producto energético más apreciado, colocó a Venezuela en un lugar privilegiado que se tradujo en dinero fácil, y por consecuencia, en crecimiento desordenado y falto de planificación." 16

16 Iván Bravo Padilla, Caracas sus esquinas, imágenes y anhelos, (Caracas, Venezuela: 
La disponibilidad de terrenos circundantes, correspondientes a las antiguas haciendas agrícolas que perdieron su rentabilidad, generosas condiciones topográficas y climáticas, presencia del automóvil, fueron factores que incitaron al sector privado a diseñar nuevas urbanizaciones ajustadas a las exigencias residenciales de familias pudientes.

Es significativo apuntar que simultáneamente-aunque en menor proporción- el estado hace lo propio e inicia una participación más directa en la producción de viviendas, paso cristalizado a través de la creación de un organismo estatal para atender la problemática. Por esta vía, el 28 de Junio de 1928, se crea el Banco Obrero dependiente del Ministerio de Fomento, con el objetivo la consecución de proyectos de financiamiento de vivienda a largo plazo y facilitar a los obreros pobres la adquisición de casas a buenos precios y buen estado sanitario.

... "a este primer momento en el que las tierras baldías nacionales o ejidos municipales eran otorgados para la construcción de viviendas, se suma sin dificultad, en una coyuntura favorable, el fomento directo del Estado al proceso de producción de viviendas. La creación para de ello de un organismo ad hoc, que tuviese competencia en la promoción y supervisión de la construcción, en la selección de los beneficiarios, en el otorgamiento y cobro de los créditos, le dieron al banco desde un principio un perfil definidamente administrativo; afirmado, además, por la adscripción del organismo al Ministerio de Fomento y no al Ministerio de Obras Públicas." ${ }^{17}$

Con considerables deficiencias constructivas, terrenos de difícil accesibilidad o en zonas consideradas para la fecha periféricas, los urbanizadores privados propondrán de inmediato sus proyectos al nuevo banco, que los aceptará. Producto de ello se levantan, 200 casas en San Editorial Panapo, 1988), 131.

17 Juan José Martin Frechilla. "Rotival de 1939 a 1959 De la Ciudad como Negocio", en El Plan Rotival la Caracas que no fue, ed. Marta Valltmijana, (Caracas, Venezuela: Ediciones Instituto de Urbanismo FAU-UCV, 1991), 77. 
Agustín del Sur (1928-29), 95 en Agua Salud (1928-31), 38 en Barrio Obrero Catia (1928-30) y 72 en los Jardines del Valle (1928-29).

Como se ha podido observar el proceso de trasformación urbana de Caracas en el período 1926-1936, se caracterizó por la actividad descollante de la empresa privada. La administración pública otorgó libertad de acción casi completa, a las propuestas urbanas en la periferia capitalina.

Así mismo, como parte de la política oficial se instituye el mencionado Banco Obrero, un tanto semejante a los planes que adelantan algunos países industrializados, para solucionar déficits habitacionales propios. A pesar de ello, "El carácter decorativo del instituto, un gobierno sin programas en el moderno sentido de la palabra, no permite pasar, en los primeros años, del simple suministro de crédito. La muerte de Gómez y la subida a la presidencia de su sucesor designado, López Contreras, abre una etapa de consciente y tímido desbloqueo socio político tendiente a una actualización del país que conlleva un paso de regularización de las instituciones gubernamentales" 18

La ausencia de un proceso de industrialización sostenido que requiriese mano de obra calificada y estable, de una clase obrera propiamente dicha que, a su vez, demandase la vivienda como parte de sus conquistas sociales, directamente o por a través de partidos y sindicatos, relegaron la iniciativa del Estado venezolano en la vivienda, a la esfera económica-financiera. Habría que esperar a 1936, y de ahí en adelante, para que apareciese en los programas de los partidos políticos como una reivindicación y un reclamo la efectiva mejora y saneamiento de las viviendas de las clases trabajadoras. ${ }^{19}$

18 Bernardo Moncada Cárdenas. El proyecto de renovación urbana de El Silencio y la arquitectura moderna en Venezuela, (Caracas: Venezuela, Ediciones Copográfica, 2000), 46 19 Frechilla. "Los Orígenes del Interés Social en las Políticas Pública de Vivienda en Venezuela $1911-1941 ", 87$. 


\section{Surgimiento y Consolidación de instituciones públicas rectoras de orden urbano.}

La ciudad de Caracas se reconoce en América Latina por el particular tipo de crecimiento urbano desarrollado a partir de la década de los treinta y cuarenta. Este crecimiento, apoyado por el espectacular ingreso proveniente del aprovechamiento de los recursos petroleros explotados fue moldeando una forma de hacer ciudad que se caracterizó por estar fuertemente influenciada por la corriente modernista que se imponía en ese momento.

Los tipos de agrupaciones residenciales que caracterizaron el comienzo del siglo XX, en los centros urbanos presentaban una morfología donde se destacaba un centro formado por casas coloniales o inspiradas en éstas y que estaban localizadas en manzanas. El resto eran los denominados ranchos o casas humildes, que se ubicaban en los alrededores.

La Caracas de 1936 reducto de la ciudad de techos rojos, presenciaba la irreversible mutación de la que era objeto; bajo el propagado ímpetu deseo de "modernización”; una vez fragmentada su unidad tradicional, la ciudad pasa a ser dos realidades: Por una parte estaba la reticulada urbe- herencia colonial persistente -que había logrado el deseado nivel de ornato y de infraestructura, de concentrados usos administrativos, recreacionales y comerciales. Por otra parte, la ciudad esparcida, seccionada, fragmentada; de exclusivo uso residencial y con una conducta en común, su expansión hacia el Este.

El mecanismo de unión entre la vieja y nueva ciudad era el automóvil y en atención a él había que pensar. Para 1936 estaban presentes y eran discutidos los nuevos modelos de la modernidad: vías amplias y edificios aislados con fachadas libres para la ventilación e iluminación de los ambientes. "Los dilemas urbanos de la capital lopecista fueron catalizados por el problema 
del tráfico el cual siguió empeorando a pesar de la implementación de infructuosas medidas

Un hecho relevante, el cual viene a complejizar la problemática, es que a partir de 1936 se suceden intensas movilizaciones de población hacia Caracas $^{20}$, donde comienzan a invertirse altos porcentajes del presupuesto nacional en infraestructura y servicios. Las migraciones y movilizaciones de población derivan de una descomposición de la estructura agraria, la cual prescinde de una considerable mano de obra, que será absorbida en parte por la actividad petrolera; pero que en su mayoría pasará a formar parte de la llamada población marginal en el área metropolitana de Caracas específicamente en sus zonas adyacentes informales.

Para el nuevo período que se iniciaba en el país entre 1936 a 1941, se demostró el interés del gobierno, presidido por el General Eleazar López Contreras; en impulsar mejoraras en las condiciones de vida del caraqueño y del venezolano en general. ${ }^{21}$ Un mérito en la administración lopecista fue el dar visos de la democratización de la educación, el saneamiento y el urbanismo; parte de estas transformaciones fueron respuestas institucionales al crecimiento demográfico que continuaba en su vertiginoso ascenso de la década del 30.

"La administración lopecista introdujo (...) instituciones e instrumentos de urbanismo municipal, los cuales serían tomados como modelos para el resto del país, así como para futuras oficinas de planificación urbana a escala nacional." ${ }^{22}$

Se nota una transformación en Caracas, referida tanto al aspecto arquitectónico como al 20 A la muerte de Gómez, la capital recupera su sitial de "honor" en el privilegio e inversión en obras de infraestructura y servicios.

21 Durante el mandato de López Contreras el Congreso aprobó la Ley del Trabajo, que estableció la jornada de ocho horas y el derecho a prestaciones sociales de los obreros.

22 Arturo Almadoz. La ciudad en el imaginario venezolano,(Caracas, Venezuela: Fundación para la Cultura Urbana, 2004, p. 49. 
conglomerado humano y a la actividad total de la ciudad. El gobierno de López Contreras, intento desarrollar una política de planificación de obras públicas, sobre todo para Caracas, sin embargo la confrontación bélica mundial constituyó una circunstancia adversa para llevar a cabo dichos planes, las exportaciones agrícolas del país se ven afectadas tras la caída mundial de precios.

"La capital de país, como centro de concentración de los poderes, de la vida política, social y cultural, percibe con mayor fuerza la radicalidad de esos cambios. Entonces se deseaba estar "a la altura" de las grandes capitales del mundo y por tanto era mucho más importante copiar modelos urbanisticos y arquitectónicos que estudiar nuestras condiciones climáticas, topográficas y sociales para planificar modelos de desarrollo que en realidad se correspondieran con nuestras idiosincrasias y necesidades. ${ }^{23}$

En el norte del continente a partir de 1937 se reconoce que la construcción de viviendas para los sectores de menores recursos es un problema de gobierno, por tanto se instituye la United States Housing Autority amparada en la Wagner-Steagall Housing Bill. A través de este mecanismo se reconocía que el sector privado no estaba capacitado para resolver el problemática devenida de la escasez de viviendas decentes, seguras y sanas; aplicándose una mayor participación del Estado.

En la ciudad de Buenos Aires, se celebra el Primer Congreso Panamericano de la Vivienda Popular, donde se discute la problemática de densidad en América latina, estrategias para la construcción de viviendas a sectores de bajos recursos, la planificación urbana y la participación decisiva de los estados nacionales. La experiencia del encuentro se sentirá en tierras venezolanas.

23 Bravo, 131. 
En Venezuela desde su conformación como nación independiente y precisamente a partir del mandato del General Antonio Guzmán Blanco la principal esencia de los procesos urbanos es la política urbana. Todo planteamiento de infraestructura, desarrollos habitacionales, rediseño urbano, etc. pasa fundamentalmente por la mediación política y en particular por el aparato del estado.

"El estado es un actor en la construcción de la ciudad, actúa como promotor y agente financiero de la construcción para sectores medios, medios-bajos y a veces de altos ingresos - muy escasamente para la población de más bajos recursos- como regulador de la actividad privada y como constructor de los servicios de infraestructura"24

La decisión para proceder a la ejecución de un plan directivo-organizador, de acuerdo con los principios y realidades propias, nace de manos de la Acción Gubernamental. Un programa de acción, esencialmente continuo y progresivo a fin de alcanzar los objetivos, es estructurado entonces, en sintonía con las disponibilidades financieras, técnicas y públicas. Lo realmente plausible y trascendental de la gestión lopecista incide en el despertar de esa conciencia planificadora y la necesidad imperante de ejecutar decisivamente estudios formales que permitiesen la consecución de planes urbanos rectores.

No obstante “...En cada uno de los programas o acciones dirigidos hacía los sectores de la población en zonas de marginalidad ecológica, se verifica que las acciones no han respondido a planes generales de desarrollo; sólo han sido demostración de una "dinámica" para cubrir las exigencias de satisfacción de necesidades colectivas (...) donde la inversión realizada produce

24 Nora Clichevsky. Construcción y Administración de la Ciudad Latinoamericana, (Argentina: Grupo editor Latinoamericano, 1990), 17. 
un afianzamiento de las bases de la segregación social” 25

El preverse de una casa higiénica, económica, favorecida por el correcto uso de la luz y ventilación y de técnicas constructivas contemporáneas; correspondieron más al discurso oficial que a la posibilidad concreta de que esas bondades fuesen proporcionadas a los sectores populares, quienes debido a la insuficiencia del ingreso económico debían minimizar sus gastos de alojamiento y transporte.

Aun en el caso de una oferta significativa, estas viviendas con plazos de amortización de difícil cancelación, o alejadas de los lugares de empleo y de las rutas de transporte público, no eran competencia significativa para la autoconstrucción de barrios y viviendas en quebradas y cerros, o para las casas de vecindad del centro de la ciudad.

"Hoy día se palpa con mayor diafanidad la inaplazable urgencia de que el gobierno nacional construya barrios destinados a las clases pobres de la capital. (...) La ciudad cada día crece en población, por eso destacamos la urgencia de que la acción gubernativa tienda a la construcción de barrios obreros; pero entiéndase bien: barrios obreros. No un amplio sector, poblado de casas bonitas pero habitadas de familias más o menos pudientes. ${ }^{26}$

"Un gobierno consciente de las realidades deberá construir las ciudades adoptando un nuevo plan. Este plan debe significar: construcciones de muchos pisos, que ocupen una pequeña extensión edificada, y dilatados espacios libres (...) total supresión de las plazas o patios interiores, de las calles-corredor (...) construcciones sobre pilotes para poder barrer el gas por medio de corrientes de aire, grandes instalaciones de grifos para combatir el gas por 25 Sánchez, 162.

26 EL Universal. "La escasez de vivienda en Caracas". 16 de marzo de 1942, 4. 
medio del agua. ${ }^{27}$

El mayor legado de la administración lopecista lo constituye la creación de la Dirección de Urbanismo el 6 de abril de 1938, cuyas directrices se basaron en los estudios de la organización y replanteamiento de la ciudad, centrando su atención en el casco original de la ciudad de Caracas e identificar las líneas principales para la urbanización del resto del valle. A los efectos de control se nombró en la misma fecha la Comisión Técnica de Urbanismo integrada por el Dr. Edgard Pardo Stolk y los arquitectos Carlos Raúl Villanueva, Carlos Guinand, Enrique Gracia Maldonado y Gustavo Wallis.

El Gobierno percibiendo que la ciudad había perdido su equilibrio y requería la rápida y consiente intervención, creó la mencionada institución liderizada por un grupo arquitectos y urbanistas venezolanos conjuntamente con la asesoría del urbanista francés Maurice Rotival, con la misión de buscar soluciones lógicas a todos estos problemas vitales. Uno de los resultados más trascendentales de este organismo fue la proposición del Plano Regulador de Caracas aprobado en 1939 por el Concejo Municipal de la ciudad.

"Conseguir un proyecto, firmar un contrato, promover unas ideas, adiestrar a los nuevos profesionales, trabajar en la práctica de la gestión urbana, son algunos de los ámbitos de acción del urbanismo francés en nuestro continente. Sus éxitos y fracasos, el interés que despierta, las propuesta que avala, constituyen el paradigma, hasta que la devoción por los modelos europeos se trasmuta en veneración por lo norteamericano, justo antes, durante y después de la Segunda Guerra Mundial. "28

27 S/a. "Urbanismo: División del Terreno en las Ciudades", Revista Técnica del Ministerio de Obras Públicas, (Caracas) 77 (Febrero de 1938): 783.

28 Juan José Martín Frechilla. "Rotival de 1939 a 1959 De la Ciudad como Negocio", 89. 
Transformar la ciudad, y por consiguiente la sociedad, en objetos de operación racional, crear políticas de organización y principalmente establecer la autoridad gubernamental en la ejecución de modificaciones, ampliaciones o construcciones urbanas; constituye el órgano del ideológico que los reformadores de comienzos del siglo XX comenzaran a desarrollar. En este proceso las ciencias y las disciplinas y profesiones que se desprenden asumieron un papel categórico.

Venezuela entra en la etapa idónea en que las instancias públicas de asistencia, de inspección y control sanitario orquestan instrumentos de la acción, como la realización de grandes y detalladas encuestas en los barrios populares; mientras, conjuntamente, se rediseñan los nuevos aparatos estadísticos nacionales.

El orden urbano exige, cierto orden social, llevar a la práctica esto, implicaba entonces reconocer también cuales agentes sociales pueden estar dispuestos a hacer un esfuerzo por imponer ese orden y cuales se esforzaran por buscarlo. Para el éxito de los planes de transformación, fue esencial identificar las fuerzas sociales susceptibles a dicha transformación.

...."tanto las políticas sanitarias, de profilaxia social e inmobiliaria, como las políticas públicas de vivienda, con renovación urbana, embellecimiento, erradicación y segregación incluidas, pasando como era de esperarse por la planificación y el control del desarrollo urbano, hicieron carrera entre nosotros, y nuestra urbanización sin industrialización fue enfrentada por el sector público como si aquélla fuese de ésta resultado." ${ }^{29}$

El Plan Monumental de Caracas, mejor conocido el Plan Rotival, ha sido el que mayor atención y estudios a generado, sin embrago, para la fecha se realizaron otras propuestas urbanas, 29 Marco Negrón. “4 Conferencias introductorias al estudio de la Urbanización”, 81. 
tendientes a reacondicionar el centro de la ciudad y vincularlo con los suburbios del Este. En el primer trimestre de de 1936, es publicado un artículo en el diario El Universal, que da testimonio de las dificultades funcionales, sanitarias, el tráfico en el centro de la capital y la premura de iniciar planes organizados de expansión de la ciudad.

"Caracas es y seguirá siendo un pueblo grande mientras no se proceda a un ensanche por lo menos de una de sus calles, ensanche que permitirá entonces llamarla ciudad (...) las medidas que se toman para mejorar la circulación de vehículos son inoperantes, porque el problema hoy no es de organización sino de cabida de vehículos dado que el ancho de las calles no está en relación con el número de vehículos que existen (...) para una ciudad como Caracas es poco un solo mercado y molesto y peligroso para la salud pública..." ${ }^{30}$

El autor- quien escribe desde el anonimato- propone soluciones de orden vial, legal, sanitario y estético. Considera imperioso extender una de las avenidas principales que debe servir de eje básico para venideras ampliaciones, en el ámbito legal estima la modificación del sistema de ventas de lotes, expropiaciones y controles urbanos. Sustituir el céntrico mercado de San Jacinto por un conjunto de mercados periféricos, es la solución de carácter salubre; y a nivel estético demoler un perfil de 30 metros desde el borde de la acera del lado sur del nuevo eje ${ }^{31}$ para realizar una fachada urbana moderna y uniforme.

"Dificilmente podría hablarse del urbanismo de la Caracas de la primera mitad del siglo XX sin mencionar en forma particular las acciones promovidas o emprendidas por Luis Roche (...) la experiencia de Luis Roche en la urbanización y comercialización del suelo urbano 30 El Universal, "Proyecto de ensanche para Caracas, Cómo resolver el 1er problema de congestión de tráfico", 27 de febrero de 1936, 2.

31 Gran avenida Oeste-Este de 26 metros de ancho por 3. 75 kilómetros; con la cual se uniría el casco central con la avenida Sucre al Oeste, y con la Carretera del Este. 
se inició en 1926, (...) con su participación en el Sindicato para la urbanización de San Agustín del Norte. Esta empresa dio altos dividendos, lo que permitió poco después pasar a la segunda etapa de la misma (...) Un año más tarde participa en la gestión de la urbanización La Florida (...) La práctica y la lectura, más que un formulado cuerpo de teorías urbanisticas, hacian de Luis Roche uno de los personajes de la Caracas de 1936 con mayor experiencia en la gestión urbana." 32

Luis Roche reconocía no sólo las dificultades del tráfico, sanitarias y funcionales de la capital, sino también el deterioro ambiental causado por la invasión de autos y la desenfrenada instalación de nueva infraestructura. Motivado por el clima de apertura de ideas, y tal vez, e exhortado por la propuestas para Caracas del articulista anónimo, Roche expone su alternativa urbana en el Teatro Municipal.

... "su actual vestimenta anticuada e incómoda, sea mejorada y embellecida (...) a través de (...) un plan que no sólo sea útil a la población actual sino también para las generaciones futuras, (...) para lograrlo se necesitan tres elementos: Querer entrañablemente a Caracas, y sabemos que hoy el gobierno la quiere; emprender las obras con energía a la par que con imaginación creadora (...) y en fin, no abrigar el temor de hacer las inversiones necesarias, pues todas las grandes ciudades de mundo han gastado y siguen gastando sumas cuantiosas para su mejoramiento y para su desarrollo",33

La propuesta del urbanizador estaba relacionada con el diseño de nuevas vías que parecían emular los ejemplos de New York y Paris, nuevamente la solución apunta a la ejecución de un trazado vial que atravesase el histórico centro en sentido este-oeste por la nueva Avenida Simón 32 Caraballo Perichi., 69.

33 Luis Roche "El Embellecimiento de Caracas", El Universal, 4 de marzo de 1936, 1. 
Bolívar de extensión de 36 metros. El proyecto reconocía como principales problemas el tráfico vehicular, de tipo sanitario, funcional y de ornato; el plan urbano estaba cargado de un sensible simbolismo patriótico con la incorporación de un monumento dedicado a Bolívar como remate de la avenida ${ }^{34}$.

A pesar de su relativa falta de fundamento técnico, todas estas propuestas tuvieron el mérito de entender los retos históricos de la Caracas Pos-gomecista, proclamar públicamente el agotamiento del centro colonial, cuya cuadricula había soportado intacta casi cuatro siglos de cambios sociales y económicos.

\section{Creación de un nuevo orden: Plan Monumental de Caracas.}

Luego de cierto período de inestabilidad en cuanto a la realización del Plan Monumental de Caracas, finalmente este es contratado por la Gobernación del Distrito Federal y concebido por el equipo de urbanistas franceses liderado por Maurice Rotival, el Plan Rotival como es comúnmente denominado, básicamente consistió en una propuesta urbana que consideraba incorporación de la vieja ciudad colonial a los desarrollos de mediados del siglo XX, considerando la sistematización de los avances arquitectónicos, con el fin de solucionar los problemas causados por el tan aludido congestionamiento del tránsito vehicular y la presión demográfica que ya acusaba Caracas en los años 30.

El estado no tardó en delinear una política urbanística, emplazado por la poderosa corriente de opinión pública puesta en marcha por algunos sectores intelectuales y profesionales (Colegio

34 Como coronación a la moderna avenida, se utilizaría como pedestal el parque El Calvario para colocar un enorme monumento conmemorativo. Como en las páginas siguientes veremos muchos de estos elementos se tomaran en cuenta en los proyectos urbanos por proponerse. 
de Ingenieros, Ateneo de Caracas) y de la que se hacían eco algunos funcionarios gomecistas y lopecístas. Surge así lo que hoy conocemos como el Plan Rotival, el cual nos dejará el trazado del eje divisor del norte y del sur de la ciudad.

El Plan Rotival presenta una propuesta urbana, no sólo cargada del alto sentido ornamental y suntuoso, también incorpora el enfoque de una necesidad económica y una inversión para el futuro de la capital. El PMC otorgaba prioridad a la ejecución de obras majestuosas, presididas por la construcción de una avenida principal, extraordinarios monumentos simbólicos y conmemorativos, nuevos edificios públicos; con lo cual se reforzaba el carácter monumental del centro de la ciudad compuesto por edificaciones suntuosas producto de gestiones precedentes

A demás del esplendor de diseño Haussmaniano, múltiples principios del urbanismo francés son estimados en el Plan Rotival, su interés residía más en su contenido que en su propuesta. Rotival y Lambert desarrollaron un conjunto arquitectónico que brindaba a la ciudad un nuevo aspecto, una suerte de Campos Elíseos tropicalizados, con el compromiso de reafirmar que el carácter estético de las ciudades lo determina la ejecución de una porción de ella.

Desde el inicio de las políticas de obras públicas, impulsadas durante el período guzmancistas hasta la formulación de la propuesta Rotival, la sociedad venezolana fue receptora de una transferencia arquitectónica y urbana del continente europeo, con la proyección del Plan Monumental para Caracas, se puso fin a la imagen española de la ciudad poscolonial y a su vez, precedió la americanización de la metrópoli contemporánea.

A través de la... "formación del llamado Plan Monumental de Caracas, (...) con propiedad se inaugura la tradición moderna de planificación urbana en Venezuela, con dicho proyecto se 
inician en el país esfuerzos explícitos orientados a controlar y racionalizar por parte del estado, los procesos de ocupación del territorio." 35

Finalmente del Plan Monumental de Caracas de 1939, sólo quedó Caracas convertida en un inmenso negocio inmobiliario como corresponde al momento, al país y su circunstancia. Quedó una propuesta de trama vial con una Avenida principal que no sale de ningún lado y no llega a ninguna parte. Una futura avenida Bolívar que estará desde su origen signada por la intuición, que perderá su naturaleza, que sin el proyecto se convertirá en un descampado solar al que año tras año le irán inventado oficios.

El Plan Monumental de Caracas quedo por un tiempo reducido a un sistema de vialidad que normó el desarrollo de la ciudad hasta nuestros días, mientras que el conjunto urbano que constituyó la aspiración del Ejecutivo nacional y municipal quedó arrinconado para después tomar otros rumbos.

A partir de esta época, el país comenzó a contar instrumentos- novatos- de levantamiento de información y análisis urbano; surgen los primeros dispositivos de confrontación en cuanto a la necesidad de regular la intervención privada sobre la ciudad en el negocio inmobiliario y la responsabilidad de la participación pública. A si mismo se evidencian las primeras preocupaciones en el Concejo Municipal por ocuparse de los problemas de los barrios, en contraste con la opulencia y boato del plan.

35 Marco Negrón. Ciudad y Modernidad 1936-2000, (Caracas, Venezuela: Ediciones del Instituto de Urbanismo FAU-UCV, 2001), 45. 
Este primer Plan permite a las autoridades reconocer de manera explícita- si bien algo tardía- que la comercialización y uso del espacio en Caracas son factores que pueden afectar considerablemente la convivencia y calidad de vida y que, por tanto; no pueden ser dejados a disposición del sector privado. En tal sentido, marca un hito irreversible en las relaciones entre estado y particulares y de paso, los hace partícipes en las responsabilidades sobre el resultado final de los procesos urbanizadores.

El inicio de un nuevo gobierno para el período 1941-1945 a cargo del General Isaías Medina Angarita, viene a modificar sustancialmente el devenir de la historia venezolana; al impulsar sendas medidas en el terreno político, económico y social. En materia de obras públicas e infraestructura se realizará una de las construcciones más trascendentales y sin comparación en nuestros días.

"En 1940, en la plena guerra mundial, la administración del nuevo presidente encontró irreal y demasiado costosa la propuesta de Rotival, por lo que se decidió la construcción del primer conjunto de viviendas de interés social del país. El plan se alteró para que el "espacio ceremonial institucional" propuesto por Rotival, se sustituyera por el "espacio de la ciudadanía", en donde lo simbólico deja espacio a lo utilitario". ${ }^{36}$

En cuanto a la aplicación del Plan Rotival, las prioridades del nuevo gobierno fueron otras, la renovación urbana de la barriada popular de El Silencio planteó diferencias sustantivas en la concepción y usos establecidos por dicho plan. Las medidas gubernamentales, ampliamente apoyadas por el Banco Obrero, se orientaran a sustituir el Palacio Federal y las edificaciones

36 Vicente Martínez Balda. La reconquista del Espacio Público, Caracas, Venezuela: FAU-UCV, 2000), 42. 
públicas, por un conjunto de edificios de apartamentos y comercio para la clase obrera. Sólo la Plaza Monumental, aunque de dimensiones mucho más modestas, se mantuvo, como receptora del tráfico.

Dentro de la política liberal y reformista que adelantaba el gobierno del general Isaías Medina Angarita, caracterizado por su nacionalismo favorable a la burguesía nacional, el progreso democrático y la apertura partidista y las reformas institucionales y administrativas, no tenía sentido el Plan Rotival. El Nuevo Presidente de la República, en plenas dificultades de abastecimientos en la II Segunda Guerra Mundial, se aventurará a reurbanizar el insalubre y penoso sector.

\section{Conclusión}

Caracas en su devenir histórico ha reflejado una serie de cambios y transformaciones en su trama urbana y arquitectónica, la cual fue transfigurándose en función de gustos, necesidades e ideologías de sus gobernantes.

Esa ciudad de los techos rojos, que en un momento se vio engalanada de construcciones afrancesadas, fue evolucionando presurosamente a un ritmo implacable. El crecimiento poblacional y la bonanza petrolera de las primeras décadas del siglo XX, dieron origen a la mutación de muchos de sus rincones y espacios, que resultaban abarrotados y carentes de una organización urbana bien concebida.

El Plan Rotival, fue un proyecto que evidenció el despertar de esa conciencia planificadora y la necesidad imperante de ejecutar decisivamente estudios formales que permitiesen la consecución de planes urbanos rectores. 
Aunque básicamente consistió en una propuesta urbana que consideraba incorporación de la vieja ciudad colonial a los desarrollos de mediados del siglo XX, considerando la sistematización de los avances arquitectónicos, con el fin de solucionar los problemas causados por el tan aludido congestionamiento del tránsito vehicular y la presión demográfica que ya acusaba Caracas en los años 30. Vislumbraba una propuesta no sólo cargada del alto sentido ornamental y suntuoso. Sino que además promovía la formación de una tradición moderna de planificación urbana en Venezuela, con este proyecto se encaminan serios esfuerzos a fin de controlar y racionalizar por parte del gobierno todos aquellos procesos de ocupación del territorio.

De esta forma, se tomaba como punto de partida en este proyecto la demolición definitiva del arrabal de El Silencio, y en su lugar la instauración de un eje ceremonial. Pero precisamente, en la concepción del "Nuevo ideal Nacional" del presidente Isaías Medina Angarita, gobierno caracterizado por su nacionalismo favorable, por el progreso democrático, la apertura partidista y las reformas institucionales y administrativas, no adquiría ningún sentido una obra de vasto contenido ornamental. Con ello no se le daba solución a los principales problemas que afectaba a la sociedad caraqueña de otrora.

Por tanto la importancia del mencionado Plan Rector Urbano radica en su valor de cambio y transformación y a la fecha a sido el único planeado por una comisión única y exclusivamente dedicado a ello. Su mayor valor y alcance es que a través de el la ciudad de Caracas inicia un ordenado y pensado proceso de modernización, lamentablemente careció de seguidores y sólo quedó como una normativa. 